СЛУЧАЙ МОЛНИЕНОСНОГО

ТЕЧЕНИЯ АНЦА-НЕГАТИВНОГО

ВАРИАНТА ГРАНУЛЕМАТОЗА

ВЕГЕНЕРА С ПЕРВИЧНЫМ

\section{ПОРАЖЕНИЕМ ЛОР-ОРГАНОВ}

Д. Фернандо ${ }^{1-3}$, кандидат медицинских наук,

В. Шпотин ${ }^{1-3}$, доктор медицинских наук,

А. Гостюнин ${ }^{1}$,

С. Кудаев ${ }^{4}$

${ }^{1}$ Александро-Мариинская областная клиническая больница,

Астрахань

${ }^{2}$ Астраханский государственный медицинский университет

${ }^{3}$ Астраханский фрилиал Научно-клинический центр

оториноларингологии ФМБА России

${ }^{4}$ Патологоанатомическое бюро, Астрахань

E-mail: dinafernando.lor@gmail.com

DOI: 10.29296/25877305-2018-01-25

Описан редкий случай АНЦА-негативного варианта гранулематоза Вегенера с тяжелым, молниеносным течением, манифестировавший первичным поражением ЛОР-органов.

Ключевые слова: ревматология, гранулематоз Вегенера, гранулематоз с полиангиитом, антинейтрофильные цитоплазматические антитела, антинейтросильные цитоплазматические антитела (АНЦА).

$\Gamma$ ранулематоз с полиангиитом (гранулематоз Вегенера ГВ) представляет собой редкое иммунозависимое заболевание, которое характеризуется гранулематозно-некротическим системным васкулитом, наиболее часто вовлекающим в патологический процесс верхние дыхательные пути с дальнейшим поражением легких и почек [1]. ГВ может возникать в любом возрасте, но наиболее часто манифестирует в возрасте 25-55 лет. Распространенность ГВ в последние годы увеличивается и, по данным литературы, в настоящее время в странах Европы составляет до 5 на 100 тыс. населения [2].

Для постановки диагноза ГВ необходимо наличие у больного 2 признаков из 4 (критерии Американского колледжа ревматологов):

• признаки поражения верхних дыхательных путей, язвы слизистой оболочки рта;

- наличие инфильтратов или полостей при рентгенографии легких;

- мочевой синдром в виде микрогематурии или эритроцитарных цилиндров;

- гистологические изменения в виде гранулематозного воспаления стенок артерий или артериол или в периваскулярном пространстве в биоптате [3].

Механизм возникновения заболевания объясняют иммунной дисфункцией, когда клетки иммунной системы организма и вырабатываемые ими агрессивные вещества начинают атаковать собственные ткани и органы. Имеются сведения о возможной генетической предрасположенности. Иммуногенетическими маркерами являются антигены HLAB7, B8, DR2 [4].
В результате повреждения тканей вследствие воздействия инициирующего воспалительного процесса развивается весьма специфический иммунный ответ. Часть этого ответа направлена против ранее экранированных эпитопов белков гранул нейтрофилов, что приводит к высоким титрам аутоантител, известных как антинейтрофильные цитоплазматические антитела (АНЦА). За этим нередко следуют развитие синдрома диссеминированного внутрисосудистого свертывания (ДВС), нарушение микроциркуляции. Образование АНЦА считается характерным признаком ГВ в большинстве случаев и используется для ранней диагностики. По данным литературы, чувствительность и специфичность этого теста превышают 70\%. На основании данного факта ГВ относят к числу так называемых АНЦА-васкулитов.

Тем не менее почти у $20 \%$ пациентов с ГВ тест на АНЦА дает сомнительный результат, у $10 \%$ ГВ относят к так называемым АНЦА-отрицательным формам [5, 6]. Причиной этого может быть ранняя стадия заболевания с локальным поражением верхних дыхательных путей, а также ремиссия на фоне медикаментозного лечения. Выделяют несколько подтипов АНЦА, из которых для ГВ наиболее характерно выявление АНЦА к миелопероксидазе и протеиназе-3 [7, 8].

В дебюте заболевания самый частый признак - поражение верхних дыхательных путей. В развернутой стадии оно возникает у 90-94\% больных и характеризуется упорным ринитом с гнойно-геморрагическим отделяемым и изъязвлением слизистой оболочки носа. Возможно формирование седловидной деформации носа из-за деструкции костных и хрящевых структур. Помимо ринита, возможны патологические изменения в трахее, придаточных пазухах носа, полости рта, гортани и среднем ухе с последующим формированием гранулем. При объективном исследовании в полости носа (ПН) слизистая оболочка резко отечна, гиперемирована, не сокращается под действием адреналина, дыхание через нос затруднено; как правило, отмечаются гнойные выделения из носа, носовые кровотечения, язвенные изменения слизистой оболочки [9].

За период 2014-2017 гг. в Александро-Мариинской областной клинической больнице Астрахани были пролечены 5 пациентов с ГВ (1 женщина и 4 мужчин) в возрасте от 32 до 67 лет. Двое пациентов с локальными поражениями ЛОРорганов и орбиты первоначально были госпитализированы в соответствующие специализированные отделения для купирования угрожающих жизни состояний с дальнейшим лечением у ревматолога. У одного из них был выявлен АНЦАнегативный вариант ГВ.

Пациент, 53 лет, обратился в ЛОР-отделение в январе 2017 г. Доставлен с жалобами на пульсирующую головную боль и боль в носу, наличие плотного, крайне болезненного инфильтрата в области наружного носа, гнойные выделения из носовых ходов с резким гнилостным запахом, выраженное затруднение носового дыхания, фебрильную (до 40ㄷ) температуру тела.

Ранее находился на стационарном лечении в другом регионе с диагнозом: абсиесс носовой перегородки, реактивный отек нижних век. Новообразование ПН слева. Согласно выписке из истории болезни, первые симптомы заболевания появились в декабре 2016 г. (около 1,5 мес назад). По месту жительства пациенту проведено комплексное противовоспалительное лечение со вскрытием и дренированием абсцесса, выполнена биопсия новообразования носа. Результат патогистологического исследования - железисто-фиброзный полип. В связи с ухудшением состояния направлен в Астрахань. 
Объективно на момент обращения в АлександроМариинскую областную клиническую больнииу: наружный нос деформирован из-за выраженной инфильтрации мягких тканей. Кожа наружного носа ярко гиперемирована, гипертермирована, заметно напряжена, пальпация резко болезненна. Имеется рана от ранее выполненного хирургического вмешательства (дренирование абсцесса). Носовые ходы значительно сужены вследствие отека и инфильтрации, из-за чего задние и средние отделы ПН необозримы. В передних отделах, в области преддверия ПН слева имеется бугристое, контактно кровоточащее новообразование небольшого размера. В просвете носовых ходов - обильное гнойное отделяемое с резким запахом. Носовое дыхание почти отсутствует. Остальные ЛОР-органы без особенностей.

При компьютерной томографии (КT) придаточных пазух носа в проекции спинки носа, мягких тканей лица, лобной области определен крупный мягкотканный компонент с наличием газа и жидкости без резких контуров и границ. Костные стенки боковых скатов носа истончены, отмечена их частичная деструкция. Перегородка носа в хрящевом отделе полностью разрушена (рис. 1).

Клинический диагноз: абсцесс наружного носа; остеомиелит носовых костей; конъюнктивит обоих глаз.

По неотложным показаниям под общей анестезией наружным разрезом вдоль боковых скатов носа с обеих сторон выполнено вскрытие абсцесса с секвестрэктомией. Операционные находки: некротизированные ткани, густое гнойное отделяемое, деструктивная полость, распространяющаяся на спинку носа и боковые скаты. Кости носа слева истончены, в верхних отделах, в проекции сочленения носовых костей с лобной костью имеется костный дефект размером 0,5×1,0 cм, неправильной формы. Край грушевидного отверстия и передние отделы сошника кариозно изменены, обнаружены узурация костной ткани в области естественных швов и свободно лежсащий костный секвестр. Хрящевой отдел носовой перегородки деструктивно полностью разрушен. Произведены некрэктомия до здоровой кости, дренирование гнойных полостей. Новообразование в преддверии ПН резецировано.

Лабораторные показатели общего анализа крови и мочи - без патологических изменений. Отмечено повышение уровня фибриногена крови и увеличение концентрации С-реактивного белка до 41,6 мг/л. Ревматоидные факторы - <8; тест на АНЦА - отрицательный. При микробиологическом исследовании выделены Streptococcus viridians $u$ Enterococcus faecalis.

В отделении получал комплексное лечение: сочетание нескольких антибактериальных препаратов, дезинтоксикационные, антигистаминные препараты, антикоагулянты и антиагреганты. Раны ежеедневно промывались раствором антисептиков. Гистологическая верификация удаленного новообразования: смешанная гемангиома с воспалением, избязвлением.

$B$ послеоперационном периоде - значительное улучшение общего самочувствия. Стихание гнойновоспалительного процесса сопровождалось уменьшением выраженности синдрома системной воспалительной реакции с нормализацией температуры тела, купированием болевого синдрома и исчезновением гнилостных выделений из носа.
C положительной клинической динамикой на 14-е сутки после операции больной выписан для дальнейшего наблюдения и лечения у хирурга и ЛОР-врача по месту жительства.

Госпитализирован в хирургическое отделение районного стационара. На фоне продолженного лечения значительное ухудшение общего состояния, в связи с чем через 7 дней больной вновь доставлен родственниками в Астрахань (рис. 2).

На момент повторной госпитализации больной предъявлял жалобы на значительное усиление боли $и$ чувства «распирания» в области надпереносья и лба, субфебрилитет, общее недомогание, значительную слабость.

Объективно: мягкие ткани в области наружного носа, надпереносья значительно отечны, инфильтрированы. Заметно увеличились пастозность и отек нижних век обоих глаз. Послеоперационные раны частично зажили вторичным натяжением, частично зияют с обнажением носовых костей. Ранее интактные участки костной ткани приобрели признаки кариозных изменений. На КТ придаточных пазух носа - состояние после вскрытия абсцесса носа; усилились явления инфильтраиии мягких тканей наружного носа; появились признаки экссудативного фронтита, вероятно, реактивного.

Под наркозом пациенту выполнена ревизия послеоперационных ран с повторной биопсией. Операционные находки: в области мягких тканей надпереносья и наружного носа визуализированы новообразованные патологические ткани хрящевой плотности с распадом, распространяющиеся из клеток решетчатого лабиринта
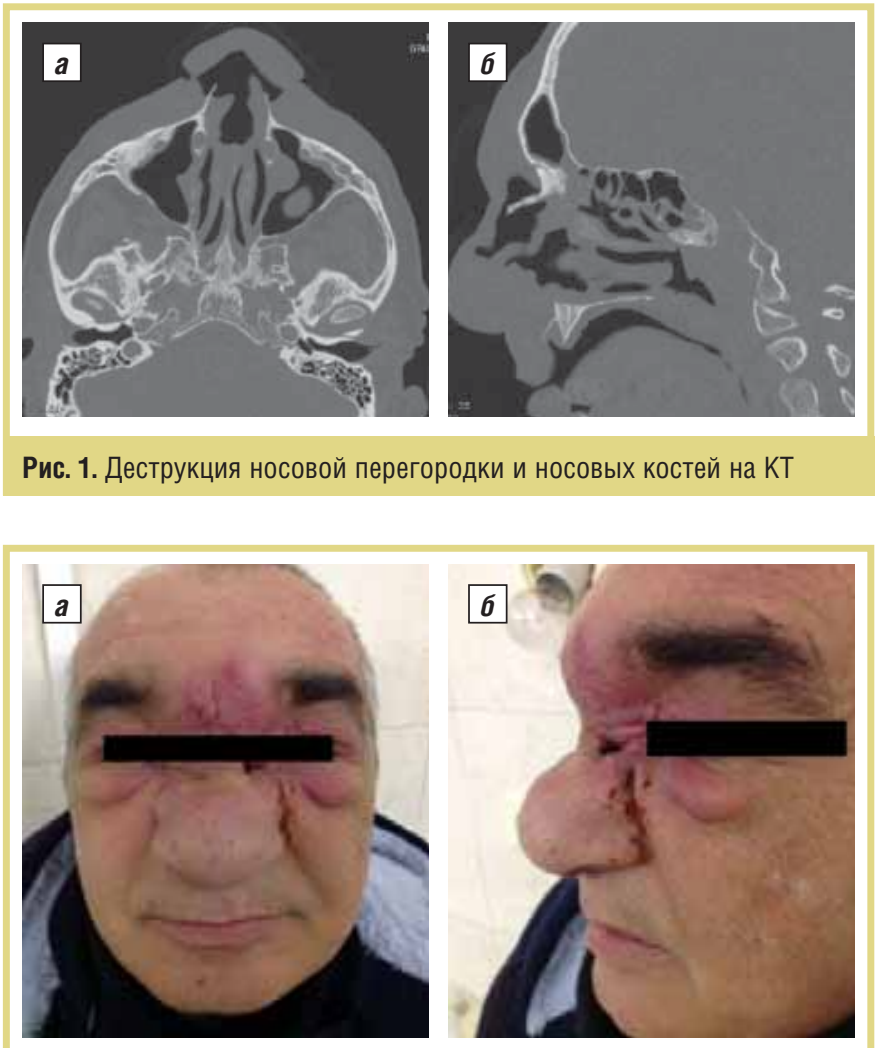

Рис. 2. Пациент при повторном обращении (отрицательная динамика после кратковременного улучшения состояния) 
и носовых раковин; при ревизии ПН обнаружены некротизированные носовые кости и сошник, скудное гнойное отделяемое. Выполнена некрэктомия, из нескольких участков повторно взяты биоптаты (рис. 3).

$B$ послеоперационном периоде состояние больного кратковременно улучшилось - в течение 2 сут после операции практически отсутствовал болевой синдром, общее самочувствие - положительной динамикой, появился аппетит.

Консервативная терапия продолжена. Однако на 3-и сутки после вмешательства общее состояние больного стало прогрессивно ухудшаться, появился критический болевой синдром, потребовавший добавления $\kappa$ лечению наркотических анальгетиков; стал быстро нарастать отек мягких тканей лица.

При повторном гистологическом исследовании обнаружены признаки некротического васкулита, эндартериита, периартериита с деструктивными и пролиферативными явлениями; выставлен патоморфологический диагноз ГВ.

На рис. 4, а-визуализируется сосуд с выраженным периваскулярным склерозом, склерозом его стенок и лимфолейкоцитарной инфильтрацией, на рис. 4, бобтурирующие смешанные тромбы в просвете сосудов.

После верификации диагноза пациент госпитализирован в ревматологчческое отделение по месту жительства. Стационарно был проведен короткий курс лечения цитостатиком, назначены постоянная гормональная терапия (преднизолон), наркотические анальгетики.

В течение 1 мес после постановки диагноза локально отмечались прогрессирующая деструкция лицевых
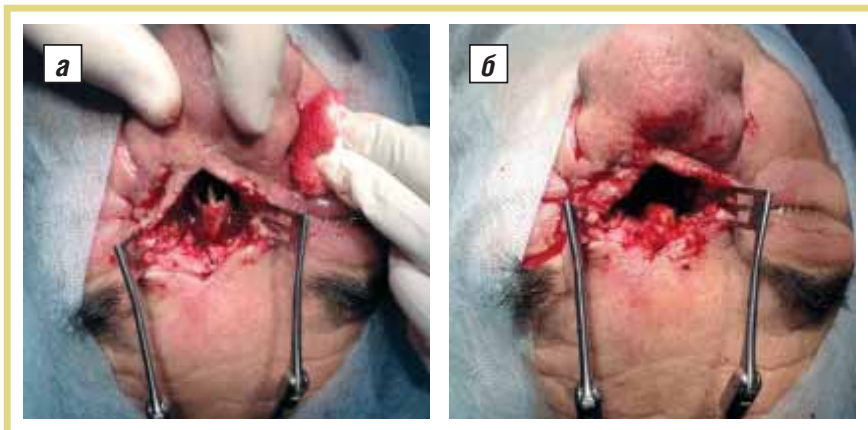

Рис. 3. Ревизия послеоперационных ран под наркозом с повторной биопсией
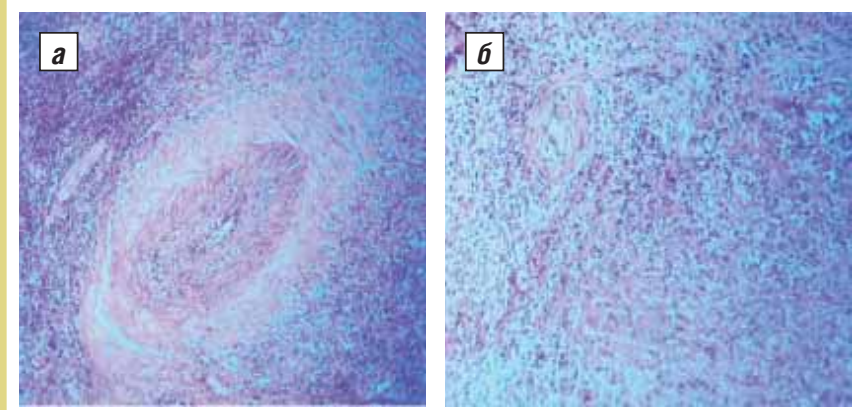

Рис. 4. Микрофротографии гистологических препаратов операционного материала костей, полный лизис медиальной и латеральных стенок ПН с формированием обширных дефектов, перфорации твердого нёба. Возникали эпизодические аррозивные кровотечения. За это время купировался болевой синдром, и впервые за 3 мес заболевания появилась и стала быстро нарастать легочная симптоматика. Летальный исход наступил через 2,5 мес после диагностики ГВ. Ориентировочная продолжительность заболевания $c$ момента появления первых симптомов (со слов больно-

го) составила около 4 мес.

Наблюдаемый случай АНЦА-негативного варианта ГВ протекал в ограниченной форме и характеризовался молниеносным течением. Особенность его заключалась в локальном поражении верхних дыхательных путей с выраженной деструкций мягких тканей и костей лица без признаков системных изменений.

Таким образом, только ранняя диагностика ГВ, учитывая тяжесть заболевания и его неблагоприятное течение, позволяет достичь хотя бы временного улучшения качества жизни пациентов и продления периода ремиссии. При выявлении плохо купируемых рецидивирующих гнойно-деструктивных поражений верхних дыхательных путей, глаз и кожи лица целесообразно в максимально короткие сроки провести расширенное гистологическое исследование тканей, даже при наличии АНЦА-отрицательных тестов.

\section{Литература}

1. Allen S., Harvey C. Imaging of Wegener's granulomatosis // Br. J. Radiol. 2007; 80: 757-65.

2. Mohammad A., Jacobsson L., Westman K. et al. Incidence and survival rates in Wegener's granulomatosis, microscopic polyangiitis, Churg-Strauss syndrome and polyarteritisnodosa // Rheumatology (Oxford). - 2009; 12: 1560-5.

3. Leavitt R., Fauci A., Bloch D. et. al. The American College of Rheumatology 1990 criteria for the classification of Wegener's granulomatosis // Arthritis Rheum. - 1990; 33: 1101-7.

4. Зубкова Л.Л., Балданова И.Р., Борхонова И.В. и др. Гранулематоз Вегенера (случай из практики) // Вестн. Бурятского гос. университета. - 2009; 12: $99-101$.

5. Kashiwagi T., Hayama N., Fujita E. et al. A case of (double) ANCA-negative granulomatosis with polyangiitis (Wegener's) // CEN Case Reports - 2012; 1 : $104-11$.

6. Savige J., Pollock W., Trevisin M. What do antineutrophil cytoplasmic antibodies (ANCA) tell us? // Best Pract. Res. Clin. Rheumatol. - 2005; 19 (2): $263-76$.

7. Hagen E., Daha M., Hermans J. et al. Diagnostic value of standardized assays for anti-neutrophil cytoplasmic antibodies in idiopathic systemic vasculitis. EC/BCR Project for ANCA Assay Standardization // Kidney Int. - 1998; 53 (3): 743-53.

8. Hoffman G., Specks U. Antineutrophil cytoplasmic antibodies // Arthritis Rheum. - 1998; 41 (9): 1521-37.

9. Pagnoux C., Wolter N. Vasculitis of the upper airways // Swiss. Med. Wkly. 2012; $142: 13541$

\section{A CASE OF FULMINANT ANCA-NEGATIVE WEGENER'S GRANULOMATOSIS WITH PRIMARY ENT INVOLVEMENT}

D. Fernando ${ }^{1-3}$, Candidate of Medical Sciences; V. Shpotin ${ }^{1-3}, M D ;$ A. Gostyunin ${ }^{1}$

\section{S. Kudaev}

${ }^{1}$ Aleksandro-Mariinsk Regional Clinical Hospital, Astrakhan

${ }^{2}$ Astrakhan State Medical University

${ }^{3}$ Astrakhan Branch, Otorhinolaryngology Research and Clinical Center, Federal Biomedical Agency of Russia

${ }^{4}$ Postmortem Examination Bureau, Astrakhan

The paper describes a rare case of ANCA-negative Wegener's granulomatosis with a severe, fulminant course, which is manifested by primary ENT involvement. Key words: rheumatology, Wegener's granulomatosis, granulomatosis with polyangiitis, antineutrophil cytoplasmic antibodies (ANCA). 